\title{
Non-invasive mechanical ventilation after heart surgery in children
}

\author{
Sarah Fernández Lafever ${ }^{1,2 *}$, Blanca Toledo ${ }^{1,2}$, Miguel Leiva ${ }^{1,2}$, Maite Padrón ${ }^{1,2}$, Marina Balseiro ${ }^{1,2}$, Angel Carrillo ${ }^{1,2}$ \\ and Jesús López-Herce 1,2,3* $^{*}$
}

\begin{abstract}
Background: The purpose of the study was to analyze the characteristics and evolution of non-invasive mechanical ventilation (NIV) in the postoperative period of heart surgery in children.

Methods: Retrospective observational study including all children requiring NIV after heart surgery in a single center pediatric intensive care unit (PICU) between 2001 and 2012. Demographic characteristics, ventilation parameters and outcomes were registered, comparing the first 6 years of the study with the last 6 years.

Results: 935 children required invasive or non-invasive mechanical ventilation, of which 200 (21.4) received NIV. The median duration of NIV was 3 days. Mortality rate was 3.9\%. The use of NIV increased from 13.2\% in the first period to $29.2 \%$ in the second period $(p<0.001)$. Continuous positive airway pressure (CPAP) was the most common modality of NIV (65.5\%). The use of bilevel positive airway pressure mode (BIPAP) increased from 15\% in the first period to $42.9 \%$ in the second period $(p<0.001)$. The nasopharyngeal tube was the most common interface $(66 \%)$, but the use of nasal cannula increased from 3.3 to $41.4 \%$ in the second period $(p<0.001)$. NIV failed in $15 \%$ of patients. The mortality rate did not change, the duration of NIV decreased and the PICU length of stay increased throughout the study.

Conclusions: NIV is increasingly being used in the postoperative period of heart surgery in our center with an $85 \%$ success rate and is associated with a lesser need for invasive mechanical ventilation. CPAP was the most common modality and the "nasopharyngeal tube" was the most common interface in our study although, in the latter years, the use of BIPAP and nasal cannula has increased significantly.
\end{abstract}

Keywords: Non-invasive ventilation, Heart surgery, Children

\section{Background}

Outcomes in children after heart surgery depend on the severity and complexity of the underlying heart disease, preexisting conditions, duration and complications during surgery and clinical evolution in the postoperative period [1].

The use of mechanical ventilation in the postoperative period has an important impact on hemodynamics and clinical evolution [2,3]. Several studies have found an association between mechanical ventilation in children after heart surgery and an increased risk of mortality, longer pediatric intensive care unit (PICU) length of stay (LOS) and greater costs $[4,5]$.

\footnotetext{
*Correspondence: sarahlafever@gmail.com; pielvi@hotmail.com ${ }^{1}$ Pediatric Intensive Care Unit, Hospital General Universitario Gregorio Marañón, Calle Dr. Castelo 47, 28009 Madrid, Spain

Full list of author information is available at the end of the article
}

For all these reasons, an early extubation is recommended if the hemodynamic situation after surgery is acceptable [6]. Several studies have analyzed the factors that are associated with a prolonged extubation after heart surgery in children $[7,8]$, but there are no studies that analyze whether there is an association between NIV and the duration of invasive mechanical ventilation (IMV) and PICU LOS.

The aim of this study was to analyze the characteristics and evolution of pediatric patients treated with NIV after heart surgery.

\section{Methods}

A retrospective review examined the medical records of all patients between 3 days and 16 years of age requiring IMV or NIV after heart surgery in a single center PICU between the 1st of January 2001 and the 31st of December 2012. 
The study was approved by the Gregorio Marañón University Hospital Research Ethics Committee. The physician in charge of the patient established the indication and the settings of mechanical ventilation (NIV and IMV).

The following data were collected from each patient: age, sex, indication and duration of IMV and NIV, modality of NIV, continuous positive airway pressure (CPAP) or bilevel positive airway pressure (BIPAP), interface (nasal cannula, endotracheal tube in a nasopharyngeal position ("nasopharyngeal tube"), nasal mask or full face mask), NIV failure, mortality and PICU LOS. Some authors discuss whether CPAP should be considered as non-invasive mechanical ventilation but, in this study, CPAP and BIPAP are considered non-invasive modalities of mechanical ventilation.

The indication of NIV was classified into two groups: prophylactic, immediately after extubation and non-prophylactic (patients with acute respiratory failure (ARF)). Specific scales of respiratory distress were not used. The presence of respiratory failure as well as the need for intubation were based on the physician-in-charge's assessment of the patient.

The study period was divided into two groups (the first 6 years and the second 6 years) in order to study the evolution of respiratory support.

Diaphragmatic paralysis is defined as unilateral or bilateral dysfunction of the diaphragm. Initial suspicion was based on X-Ray findings (elevated diaphragm) or clinical findings (asymmetrical hemithorax excursion, abnormal breathing pattern using accessory respiratory muscles and paradoxical abdominal wall retraction during inspiration). Clinical suspicion was confirmed with M-mode ultrasonography and electromyography.

The program SPSS 18.0 was used for data analysis. Quantitative variables are expressed as medians and interquartile ranges (IQR) as data do not follow a normal distribution, and non-parametric tests were used for comparisons (Chi-square test for randomness with categorical outcomes, Man-Whitney test for comparing quantitative variables between two groups and KruskalWallis test for comparing quantitative variables between more than two groups). A $p$ value less than 0.05 was considered statistically significant.

\section{Results}

Nine hundred and thirty five patients between 3 days and 16 years of age required mechanical support after heart surgery, with a median age of 9 months (IQR 4.060.0). 59.1\% were males. The median duration of IMV was 1.5 days (IQR 0.5-7.0). The median LOS was 7.0 days (4.0-15.0), with a mortality rate of $3.9 \% .200$ patients required NIV (21.4\%) and 153 patients (16.4\%) received both IMV and NIV. Mean duration of NIV was 3 days (IQR 2.0-5.0).
Characteristics of non invasive mechanical ventilation Prophylactic NIV was the most common indication (67\%), followed by ARF (33\%). CPAP was the most common modality of NIV (65.5\%) and the "nasopharyngeal tube" was the most common interface (66\%), followed by nasal cannula (30\%), full face mask (3.5\%) and nasal mask (3\%).

The median age of children with NIV was 6 months (IQR 3.0-24.0), the duration of IMV was 8 days (4.014.5), PICU LOS was 17 days (9.0-32.0) and mortality rate was $3.4 \%$ (8 patients).

\section{Evolution of non invasive mechanical ventilation}

The study period was divided into two groups (the first 6 years and the second 6 years) in order to study the evolution of respiratory support (Table 1). The number of patients in each study period was very similar. The use of IMV decreased significantly and NIV increased in the second period, with no variations in its indication. There were no significant differences in mortality between both periods ( 3.7 vs $4.0 \%, p=0.867$ ) but mortality tended to decrease in patients with NIV ( $5.8 \%$ vs $2.4 \%, p=0.239$ ). The use of bilevel positive airway pressure mode (BIPAP) increased from $15 \%$ in the first period to $42.9 \%$ in the second period $(p<$ 0.001 ). The nasopharyngeal tube was the most common interface (66\%), but the use of nasal cannula increased from 3.3 to $41.4 \%$ in the second period $(p<0.001)$, with a significant decrease in the use of nasal masks. The duration of NIV and the PICU LOS in patients with NIV significantly decreased in the second period. The use of NIV significantly increased throughout the study period $(p<0.001)$ (Fig. 1). There was a trend toward a higher RACHS score in patients requiring NIV in the second period of the study (2.0 [2.0-3.0] vs 3.0 [2.0-3.0]) as were the number of heart transplants (8 vs 13), although these results were not statistically significant $(p=0.91$ and $p=0.452$, respectively).

\section{Comparison between invasive and non invasive mechanical ventilation}

PICU LOS in patients receiving only IMV (5.0, IQR 3.010.0) was significantly lower than those with only NIV (7.0, IQR 6.0-13.0; p 0.001). PICU LOS of patients requiring both IMV and NIV (19.0, IQR 11.0-32.5) was significantly higher than those with only IMV or NIV (p 0.001).

There was a trend to a higher mortality rate in patients receiving only IMV (4.8\%) than those receiving NIV $(0.0 \%)$ or both $(3.2 \%)$, but differences were not significant (p 0.274).

\section{Comparison according to age, indication and type of non-invasive mechanical ventilation}

The median age of children with prophylactic NIV (18.5 months), with CPAP (8.4 months) and "nasopharyngeal tube" (6.9 months) was significantly lower than 
Table 1 Comparison between study periods

\begin{tabular}{|c|c|c|c|}
\hline & $2001-2006 \%(n)$ & $2007-2012$ & $p$ \\
\hline Number of patients & $48.7 \%(455 / 935)$ & $51.3 \%(480 / 935)$ & \\
\hline Age (months) & 7 (IQR 4-48) & $12($ IQR 5-60) & $<0.001$ \\
\hline IMV & $96.7 \%(440 / 455)$ & $93.3 \%(448 / 480)$ & $<0.001$ \\
\hline NIV & $13.2 \%(60 / 455)$ & $29.2 \%(140 / 480)$ & $<0.001$ \\
\hline NIV only & $25 \%(15 / 60)$ & $22.9 \%(32 / 140)$ & 0.321 \\
\hline \multicolumn{4}{|l|}{ NIV indication } \\
\hline - Prophylactic & $65 \%(39 / 60)$ & $67.9 \%(95 / 140)$ & 0.744 \\
\hline - Acute Respiratory Failure & $35 \%(21 / 60)$ & $32.1 \%(45 / 140)$ & \\
\hline \multicolumn{4}{|l|}{ NIV type } \\
\hline - CPAP & $85 \%(51 / 60)$ & $57.1 \%(80 / 140)$ & 0.001 \\
\hline - BIPAP & $15 \%(9 / 60)$ & $42.9 \%(60 / 140)$ & \\
\hline \multicolumn{4}{|l|}{ Interface } \\
\hline - Nasopharingeal tuve & $85 \%(51 / 60)$ & $57.9 \%(81 / 140)$ & 0.001 \\
\hline - Nasal mask & $10 \%(6 / 60)$ & $0.7 \%(1 / 140)$ & 0.003 \\
\hline - Full face mask & $1.6 \%(1 / 60)$ & $3.5 \%(5 / 140)$ & 0.417 \\
\hline - Nasal cannula & $3.3 \%(2 / 60)$ & $41.4 \%(58 / 140)$ & 0.001 \\
\hline NIV failure & $20 \%(12 / 60)$ & $12.9 \%(18 / 140)$ & 0.201 \\
\hline \multirow[t]{2}{*}{ Mortality } & $3.7 \%(17 / 455)$ & $4.0 \%(19 / 480)$ & 0.867 \\
\hline & Median (IQR) & Median (IQR) & \\
\hline Duration of IMV (days) & $1.0(0.5-6.0)$ & $2.0(0.75-7.0)$ & 0.139 \\
\hline Duration of NIV (days) & $3.0(2.0-5.0)$ & $2.0(1.0-4.5)$ & 0.024 \\
\hline PICU LOS All patients (days) & $6.0(4.0-14.0)$ & $7.0(4.0-15.7)$ & 0.053 \\
\hline PICU LOS Patients NIV (days) & $22.0(9.0-35.0)$ & $14.0(8.0-23.0)$ & 0.004 \\
\hline
\end{tabular}

BIPAP bilevel positive airway pressure, CPAP continuous positive airway pressure, IMV invasive mechanical ventilation, NIV non-invasive ventilation, PICU LOS pediatric intensive care unit length of stay

the median age of those with non-prophylactic NIV (33.1 months) $(p=0.002)$, with BIPAP (48.4 months) $(p=0.001)$ and full face mask (61.5 months) or nasal cannula (60.5 months) $(p=0.001)$.

A comparison was also made between two age groups: younger than 12 months (infants) and older than 12 months (children) (Table 2).
The need for IMV was similar in both age groups, but infants required NIV more frequently. CPAP was the most common modality in infants and BIPAP in the older children. The "nasopharyngeal tube" was used mostly in infants and nasal cannula in older children.

Duration of IMV and PICU LOS was significantly higher in infants. There were no significant differences in the duration of NIV between both age groups.

\section{Non invasive mechanical ventilation failure}

41 patients $(20.5 \%)$ treated with NIV required intubation. 11 (5.5\%) for different procedures and 30 (15\%) due to NIV failure, caused by ARF in $86.7 \%$ of them and by hemodynamic instability in $13.3 \%$.

Diaphragmatic paralysis was present in one third of the patients in which NIV failed (10 patients).

NIV failure was greater in patients that had not received IMV prior to NIV, in those intubated for ARF, in those with BIPAP and in those requiring several interfaces, nasal mask or full face mask (Table 3).

The median duration of NIV was shorter in those patients in which NIV failed (2 days, IQR $0.88-3$ ) than in those in which NIV was effective (3 days, IQR 2-5) $(p=0.002)$. PICU LOS was longer in patients with NIV failure (26.5 days, IQR 17.75-40.25) than in those with NIV success $(14.0$ days, IQR $7-25)(p<0.001)$.

\section{Discussion}

Mechanical ventilation modifies lung pressures and volumes affecting preload, afterload, contractility and heart rate. Positive airway pressure may reduce pulmonary vascular resistance if it achieves appropriate alveolar recruitment and it diminishes left ventricle afterload by increasing transmural pressure. On the other hand, it decreases right ventricle preload and it increases its afterload [9].

On the counterpart, IMV increases the risk of airway damage, lung injury and infection and it is associated with a longer PICU LOS [10].

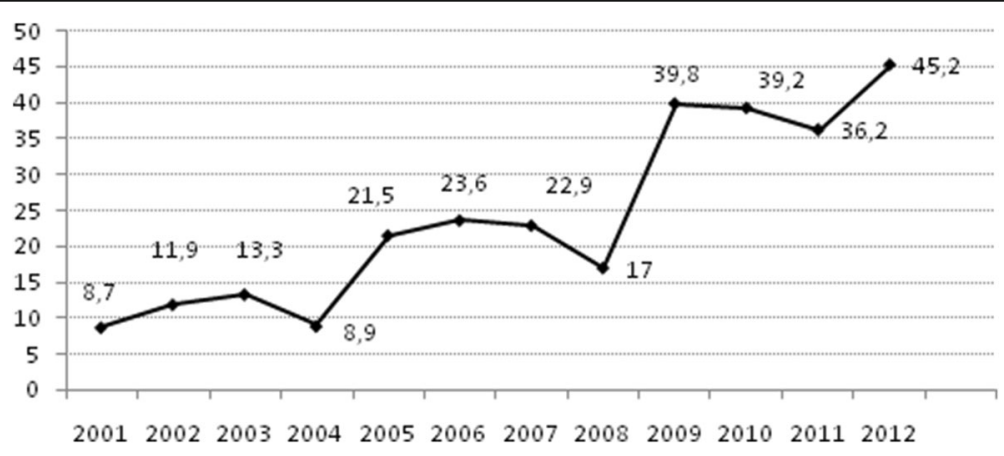

Fig. 1 Evolution in the use of non-invasive ventilation (NIV) (percentage of patients with NIV) 
Table 2 Comparison between age groups

\begin{tabular}{|c|c|c|c|}
\hline & $\begin{array}{l}<12 \text { months } \\
(n=515)\end{array}$ & $\begin{array}{l}\geq 12 \text { months } \\
(n=420)\end{array}$ & $P$ \\
\hline \multicolumn{4}{|l|}{ Periods } \\
\hline$-2001-2006$ & $54.1 \%(279)$ & $41.9 \%(176)$ & \multirow[t]{2}{*}{$<0.001$} \\
\hline - 2007-2012 & $45.9 \%(236)$ & $58.1 \%(244)$ & \\
\hline IMV & $97.6 \%(488)$ & $95.2 \%(400)$ & 1.0 \\
\hline NIV & $26.7 \%(138)$ & $14.8 \%(62)$ & $<0.001$ \\
\hline NIV only & $5.2 \%(27)$ & $4.9 \%(20)$ & 0.107 \\
\hline \multicolumn{4}{|l|}{ NIV indication } \\
\hline - Prophylactic & $71.7 \%(99)$ & $56.4 \%(35)$ & \multirow[t]{2}{*}{0.026} \\
\hline - Acute respiratory failure & $28.2 \%(39)$ & $43.5 \%(27)$ & \\
\hline \multicolumn{4}{|l|}{ NIV type } \\
\hline - CPAP & $84.0 \%(116)$ & $24.2 \%(15)$ & \multirow[t]{2}{*}{$<0.001$} \\
\hline - BIPAP & $16.0 \%(22)$ & $75.8 \%(47)$ & \\
\hline \multicolumn{4}{|l|}{ Interface } \\
\hline - Nasopharyngeal tube & $84.0 \%(116)$ & $25.8 \%(16)$ & \multirow[t]{4}{*}{$<0.001$} \\
\hline - Nasal mask & $2.2 \%(3)$ & $6.5 \%(4)$ & \\
\hline - Full face mask & $0 \%$ & $11.3 \%(7)$ & \\
\hline - Nasal cannula & $13.8 \%(19)$ & $64.5 \%(40)^{\mathrm{a}}$ & \\
\hline NIV failure & $18.8 \%(26)$ & $24.2 \%(15)$ & 0.247 \\
\hline \multirow[t]{2}{*}{ Mortality } & $4.7 \%(24)$ & $2.9 \%(12)$ & \multirow[t]{2}{*}{0.104} \\
\hline & Median (IQR) & Median (IQR) & \\
\hline IMV days & $3.0(1.0-8.0)$ & $1.0(0.4-4.0)$ & $<0.001$ \\
\hline NIV days & $3.0(1.0-5.0)$ & $2.0(1.0-6)$. & 0.572 \\
\hline PICU LOS (days) & $8.0(5.0-16.7)$ & $5.0(3.0-12.0)$ & $<0.001$ \\
\hline \multicolumn{4}{|l|}{ NIV GROUP } \\
\hline IMV days & $8.0(4.0-16.75)$ & $9.0(3.0-16.0)$ & 0.9 \\
\hline PICU LOS (days) & $16.0(8.0-27.7)$ & $15.5(9.0-31.0)$ & 0.9 \\
\hline
\end{tabular}

BIPAP bilevel positive airway pressure, CPAP continuous positive airway pressure, IMV invasive mechanical ventilation, NIV non-invasive ventilation, PICU LOS pediatric intensive care unit length of stay

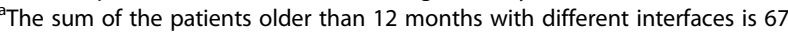
instead of 62 because 5 of these patients had several interfaces

An early extubation reduces the incidence of mechanical ventilation-related complications and it minimizes the undesired effects on heart function [11].

NIV decreases the risk of mechanical ventilationrelated complications while maintaining the beneficial heart and lung effects of positive airway pressure, enabling an earlier extubation [12-14]. Nevertheless, very few studies analyze the utility of NIV in the postoperative period of heart surgery in adults $[2,3]$ or children [14-16]. Our study is the first one to analyze NIV after heart surgery in children over a long period.

Our study shows that the use of IMV has decreased as the use of NIV has increased in our unit. This has not affected the incidence of NIV failure. The use of BIPAP, which offers greater respiratory support, as well as the use of nasal cannula (which are comfortable and well
Table 3 NIV failure according to IMV prior to NIV, indication and type of NIV

\begin{tabular}{lll}
\hline & NIV failure (\%) & $p$ \\
\hline IMV prior to NIV & & \\
Yes & $22 / 134(16.4 \%)$ & 0.046 \\
No & $19 / 66(28.7 \%)$ & \\
Indication & & 0.046 \\
$\quad$ Prophylactic & $22 / 134(16.4 \%)$ & \\
$\quad$ Respiratory failure & $19 / 66(28.7 \%)$ & 0.016 \\
Modality & \\
$\quad$ CPAP & $20 / 131(15.2 \%)$ & \\
BIPAP & $21 / 69(30.4 \%)$ & \\
\hline
\end{tabular}

BIPAP bilevel positive airway pressure, CPAP continuous positive airway

pressure, IMV invasive mechanical ventilation, NIV non-invasive ventilation

tolerated) has increased throughout the study, while the use of nasal and full-face masks has been reserved for patients with a more severe ARF.

Some of the most important factors for the success of NIV are the good tolerance and acceptance of the technique on behalf of the patients as well as an increasing experience of the PICU team.

Infants require longer mechanical ventilation and their need for NIV was greater than that of older children. This fact has been described in previous studies [6, 7]. It may be due to the greater complexity of the underlying heart disease and the surgery, to their greater metabolic requirements or to their greater dependence on diaphragmatic muscles (which can become impaired after heart surgery).

The indication for NIV was prophylactic after extubation in most of our patients for having ARF or heart failure risk factors [16]. It was not possible to analyze the efficacy of NIV in reducing the risk of failure and intubation due to the characteristics of our study. Our percentage of NIV failure is consistent with what has been published by other authors $[13,16]$. We are not able to answer the question of why NIV failure is greater with BIPAP due to the retrospective nature of our study. An important finding of our study is that the incidence of NIV failure remains stable even though overall use of NIV has significantly increased, and particularly in patients with respiratory distress. Thus, we think that patients that would have required intubation and mechanical ventilation in the first study period were successfully treated with NIV in the second period of the study.

This is why prospective comparative studies are required to assess whether prophylactic NIV after extubation decreases the incidence of ARF and re-intubation in children after heart surgery.

Patients requiring NIV had longer PICU LOS than those requiring only IMV, which could be misinterpreted 
as NIV prolonging PICU LOS. The use of NIV increased during the late study period, as did the LOS, IMV duration and the use of BIPAP. RACHS Score only takes into account surgical complexity, but not the severity of the patient's condition before and after surgery. Even so, RACHS score and the number of heart transplants was higher for patients requiring NIV in the second period of the study (although not statistically significant). All these facts may reflect an increase in the complexity and severity of illness in the second period of the study.

Our study has several limitations: it is a retrospective review including patients with a wide variety of heart diseases. Thus, the presence of certain risk factors affecting the need for and duration of mechanical ventilation, PICU LOS and mortality were not studied, such as comorbidity or changes in postoperative care [17]. The parameters and complications of NIV were not registered either [18].

\section{Conclusions}

NIV is increasingly being used in the postoperative period of heart surgery in our center with an $85 \%$ success rate and is associated with a lesser need for IMV. CPAP was the most common modality and the "nasopharyngeal tube" was the most common interface in our study although, in the latter years, the use of BIPAP and nasal cannula has increased significantly. Prospective multicenter studies are needed to better assess the association of NIV and the need for mechanical ventilation, PICU LOS and mortality.

\section{Abbreviations}

ARF: Acute respiratory failure; BIPAP: Bi-level positive airway pressure; CPAP: Continuous positive airway pressure; IMV: Invasive mechanical ventilation; IQR: Interquartile range; LOS: Length of stay; NIV: Non invasive ventilation; PICU: Pediatric intensive care unit; RACHS Score: Risk adjustment for congenital heart surgery

\section{Acknowledgements}

Not applicable.

\section{Funding}

We did not receive any funding to support our study.

\section{Availability of data and materials}

All data (database and statistical analysis) are available upon request via email to the corresponding author.

\section{Authors' contributions}

Dr. JL-H designed the study and contributed to the statistical analysis, drafting and writing of the final article. Dr. BT, ML, MP and MB contributed to the review of medical records and data collection, Dr. SF contributed to the review of medical records, data collection, statistical analysis, drafting and writing of the final article. Dr. AC contributed to the design of the study. All authors read and approved the final manuscript.

\section{Authors' information}

Sarah Fernández Lafever, Blanca Toledo, Angel Carrillo and Jesús López-Herce: Funded by the PN I + D + I 2008-2011 (Spain), ISCIII- Sub-Directorate General for Research Assessment and Promotion and the European Regional Development Fund (ERDF), ref. RD12/0026.

\section{Competing interests}

The authors declare that they have no competing interests.

\section{Consent for publication}

No specific permissions or consent for publication were obtained as no personal data are involved and data were collected retrospectively.

\section{Ethics approval}

The study was approved by the Gregorio Marañón University Hospital Research Ethics Committee.

\section{Author details}

${ }^{1}$ Pediatric Intensive Care Unit, Hospital General Universitario Gregorio Marañón, Calle Dr. Castelo 47, 28009 Madrid, Spain. ${ }^{2}$ Gregorio Marañon University Hospital Biomedical Research Foundation, Research Network on Maternal and Child Health and Development II (Red SAMID II), Madrid, Spain. ${ }^{3}$ Department of Pediatrics, School of Medicine, Complutense University of Madrid, Madrid, Spain.

Received: 28 August 2016 Accepted: 22 November 2016

Published online: 29 November 2016

\section{References}

1. Jacobs JP, O'Brien SM, Pasquali SK, Jacobs ML, Lacour-Gayet FG, Tchervenkov Cl, Austin 3rd EH, Pizarro C, Pourmoghadam KK, Scholl FG, Welke KF, Gaynor JW, Clarke DR, Mayer Jr JE, Mavroudis C. Variation in outcomes for risk-stratified pediatric cardiac surgical operations: an analysis of the STS Congenital Heart Surgery Database. Ann Thorac Surg. 2012;94:564-71.

2. Guarracino F, Ambrosino N. Non invasive ventilation in cardio-surgical patients. Minerva Anestesiol. 2011;77:734-41.

3. García-Delgado M, Navarrete I, García-Palma MJ, Colmenero M. Postoperative respiratory failure after cardiac surgery: use of noninvasive ventilation. J Cardiothorac Vasc Anesth. 2012;26:443-7.

4. Preisman S, Lembersky H, Yusim Y, Raviv-Zilka L, Perel A, Keidan I, Mishaly D. A randomized trial of outcomes of anesthetic management directed to very early extubation after cardiac surgery in children. J Cardiothorac Vasc Anesth. 2009;23:348-57.

5. Ben-Abraham R, Frati Q, Mishali D, Yulia F, Vardi A, Barzilay Z, Paret G. Predictors for mortality after prolonged mechanical ventilation after cardiac surgery in children. J Crit Care. 2002;17:235-9.

6. Mittnacht AJ, Hollinger I. Fast-tracking in pediatric cardiac surgery-the current standing. Ann Card Anaesth. 2010;13:92-101.

7. López-Herce Cid J, Leyton Avilés P, Urbano Villaescusa J, Cidoncha Escobar E, Del Castillo PJ, Carrillo Alvarez A, Bellón Cano JM. Factores de riesgo de la ventilación mecánica prolongada de niños con cirugía cardíaca. Med Intensiva. 2008;32:369-77.

8. Shi S, Zhao Z, Liu X, Shu Q, Tan L, Lin R, Shi Z, Fang X. Perioperative risk factors for prolonged mechanical ventilation following cardiac surgery in neonates and young infants. Chest. 2008:134:768-74.

9. Kocis KC, Meliones JN. Cardiopulmonary interactions in children with congenital heart disease: physiology and clinical correlates. Prog Pediatr Cardiol. 2000;11:203-10.

10. Gaboli M. Complicaciones de la ventilación mecánica. In: Grupo de Respiratorio de la SECIP, editor. Manual de Ventilación mecánica en pediatría, vol. 13. 2nd ed. Madrid: Publimed; 2009. p. 241-64.

11. Meissner U, Scharf J, Dötsch J, Schroth M. Very early extubation after openheart surgery in children does not influence cardiac function. Pediatr Cardiol. 2008:29:317-20.

12. Mayordomo-Colunga J, Medina A, Rey C, Díaz JJ, Concha A, Los Arcos M, Menéndez S. Predictive factors of non invasive ventilation failure in critically ill children: a prospective epidemiological study. Intensive Care Med. 2009; 35:527-36.

13. Abadesso C, Nunes P, Silvestre C, Matias E, Loureiro H, Almeida H. Non-invasive ventilation in acute respiratory failure in children. Pediatr Rep. 2012:4:16.

14. Zhang CY, Tan LH, Shi SS, He XJ, Hu L, Zhu LX, Zhu LX, Fan JJ. Noninvasive ventilation via bilevel positive airway pressure support in pediatric patients after cardiac surgery. World J Pediatr. 2006:2:297-302.

15. Pons Ódena M, Piqueras Marimbaldo I, Segura Matute S, Balaguer Argallo M, Palomeque RA. Aplicación de ventilación no invasiva en pacientes postoperados cardíacos. An Pediatr. 2009;71:13-9. 
16. Gupta P, Kuperstock JE, Hashmi S, Arnolde V, Gossett JM, Prodhan P, Venkataraman S, Roth SJ. Efficacy and predictors of success of noninvasive ventilation for prevention of extubation failure in critically ill children with heart disease. Pediatr Cardiol. 2013:34:964-77.

17. Székely A, Sápi E, Király L, Szatmári A, Dinya E. Intraoperative and postoperative risk factors for prolonged mechanical ventilation after pediatric cardiac surgery. Paediatr Anaesth. 2006;16:1166-75.

18. Pons M. Contraindicaciones, complicaciones y problemas técnicos. In: Medina A, Pons M, Esquinas A, editors. Ventilación no invasiva en pediatría. Madrid: Ergon; 2004. p. 81-6.

Submit your next manuscript to BioMed Central and we will help you at every step:

- We accept pre-submission inquiries

- Our selector tool helps you to find the most relevant journal

- We provide round the clock customer support

- Convenient online submission

- Thorough peer review

- Inclusion in PubMed and all major indexing services

- Maximum visibility for your research

Submit your manuscript at www.biomedcentral.com/submit
Biomed Central 